University of Wollongong

Research Online

Faculty of Engineering and Information

Faculty of Engineering and Information

Sciences - Papers: Part B

Sciences

2019

Prediction of blast furnace hearth condition: part I - a steady state simulation of hearth condition during normal operation

Xue Feng Dong

University of Wollongong, xuefeng@uow.edu.au

Paul Zulli

University of Wollongong, paulz@uow.edu.au

Follow this and additional works at: https://ro.uow.edu.au/eispapers1

Part of the Engineering Commons, and the Science and Technology Studies Commons

Research Online is the open access institutional repository for the University of Wollongong. For further information contact the UOW Library: research-pubs@uow.edu.au 


\title{
Prediction of blast furnace hearth condition: part I - a steady state simulation of hearth condition during normal operation
}

\author{
Abstract \\ A coupled flow and refractory model (CFRM) has been upgraded to assist engineers in understanding and \\ interpreting the measured refractory temperature distributions in the hearth of a blast furnace hearth. \\ CFRM describes the liquid flow distribution and heat transfer in the hearth, allowing various scenarios to \\ be simulated involving coke bed properties, extent of hearth refractory wear, etc. The model was validated \\ through comparison between measured refractory data and corresponding model predictions for the \\ early stages of the current BlueScope's No. 5 Blast Furnace campaign. For the current campaign, the \\ actual range in measured pad temperature fluctuation over a short time period is shown to be well within \\ the temperature difference expected for typical coke bed movement, i.e. between sitting and floating bed \\ conditions. Over a longer time span, a consistent evolution of the refractory wear is suggested and this is \\ imposed to elucidate the increase in overall hearth pad temperature.

\section{Disciplines} \\ Engineering | Science and Technology Studies

\section{Publication Details} \\ Dong, X. F. \& Zulli, P. (2019). Prediction of blast furnace hearth condition: part I - a steady state simulation \\ of hearth condition during normal operation. Ironmaking and Steelmaking, Online First 1-9.
}




\section{Prediction of Blast Furnace Hearth Condition: Part I - A Steady State Simulation of Hearth Condition during Normal Operation}

X.F. Dong* and P. Zulli*

Formerly of BlueScope when work was undertaken, now of School of Mechanical, Materials, Mechatronic and Biomedical Engineering, University of Wollongong, NSW 2522, Australia

Corresponding authors:

X.F. Dong and P. Zulli

School of Mechanical, Materials, Mechatronic and Biomedical Engineering, University of Wollongong, NSW 2522, Australia

Email: xuefeng.dong@uow.edu.au and paulz@uow.edu.au 


\title{
Prediction of Blast Furnace Hearth Condition: Part I - A Steady State Simulation of Hearth Condition during Normal Operation
}

\begin{abstract}
A Coupled Flow and Refractory Model (CFRM) has been upgraded to assist the operations in understanding and interpreting the measured refractory temperature distributions in the blast furnace hearth of BlueScope Steel. CFRM describes the liquid flow distribution and heat transfer in the hearth, combining these and allowing various scenarios to be simulated involving coke bed properties, extent of hearth refractory wear, etc. The model was validated through comparison between measured refractory data and corresponding model predictions for the early stages of the current BlueScope's No. 5 Blast Furnace (BF5) campaign, which covers the effects of porous media (packed bed), natural convection and turbulence on the fluid flow and conjugate heat transfer. For the current campaign to date, the actual range in measured pad temperature fluctuation over a short time period is shown to be well within the temperature difference expected for typical coke bed movement i.e. between sitting and floating bed conditions. Over a longer time span, a consistent evolution of the refractory wear is suggested and must be imposed to elucidate the increase in overall hearth pad temperature. Together with the analysis of operational conditions, the upgraded CFRM is a valuable tool to understand hearth conditions.
\end{abstract}

Keywords: blast furnace; hearth; numerical model; heat transfer.

\section{Introduction}

The hearth occupied by hot metal, slag and coke, is a critical zone of blast furnace. During normal operations, the inner state of the hearth, for example, fluid flow and coke bed condition, directly influences the casting performance and hot metal quality. More critically, the blast furnace campaign life is often dictated by the hearth refractory condition/wear. During BF shutdowns, particularly for an extended time ( 100 hours or more), the hearth cooling could significantly affect the hearth condition if the remaining liquid iron in the hearth cooled sufficiently to solidify during the shutdown period. Hence, it is important to develop a better understanding of hearth condition and corresponding wear control strategies.

Internally, it is impossible to directly measure the liquid flow, coke bed structure and the hot face refractory profile because of the high temperature conditions in the hearth. In practice, the refractory temperature distribution is extremely valuable in indicating the coke bed state and refractory erosion - for example, the cyclic variation in refractory pad temperature can be understood in light of the coke bed vertical movement. However, these temperature variations cannot sufficiently illustrate the internal liquid flow distribution and relevant bed structure. In this respect, Part I and II [1] in this two part series will apply numerical modelling to help understand the internal state of the hearth during normal furnace operation and long maintenance shutdown periods.

For normal operations, mathematical modelling, often coupled with physical modelling, has played an important role to interpret the refractory temperature distribution in terms of liquid flow distribution, coke bed properties, hearth wear condition, and so forth [215]. Turbulence flow was ignored in earlier research [2-8]. Later, the inclusion of the 
buoyancy force and k- $\varepsilon$ turbulence model in the simulation provided a real coupling between the flow and heat transfer, providing models more suitable for general use [1014]. More recently, the Shear Stress Transport (SST) turbulence model has been applied to further enhance the simulation of near-wall flow in the hearth [15].

The Coupled Flow and Refractory Model (or CFRM) was developed by BlueScope Steel Research to describe the flow of liquid iron coupled with liquid-refractory heat transfer in the blast furnace hearth $[10,11,13]$. CFRM was used throughout the last campaign of BlueScope's No. 5 Blast Furnace (BF5) to evaluate the condition of the hearth coke bed, refractories, etc. For the current campaign, the CFRM model has been reformulated and validated using ANSYS-CFX 14.5. In addition, the design changes in BF5's (4th campaign) hearth geometry including liquid bath depth and refractory arrangements, have been incorporated.

This paper details the upgrade and subsequent application of CFRM, a typical steady state numerical model used to interpret hearth refractory temperatures and understand in-furnace phenomena during normal operations in the current campaign of BF5.

\section{Mathematical modelling and boundary conditions}

\subsection{Governing equations}

The simulation of fluid flow and heat transfer in the hearth involves the solution of a fluid flow and conjugate heat transfer problem i.e. in both fluid domain (liquid bath) and solid domain (refractory). The solution fields in fluid and solid domains are fully coupled through the energy conservation at the interface between the different domains. The general governing equations for mass, momentum and energy transfer are given in Table 1.

As shown in Table 1, the following assumptions have been made in the mathematical modelling:

- The fluid flow and heat transfer in the hearth are at a steady state

- Only liquid iron is considered as the fluid phase

- The liquid iron and the coke particle in the fluid domain are at the thermal equilibrium

- As the liquid iron flows through the porous media, the thermal dispersion caused by tortuous path is isotropic

Apart from the above assumptions, special treatments have also been applied in the governing equations to consider the effects of porous media, natural convection and turbulence on the fluid flow and heat transfer in the hearth. These are listed as follows.

- Porous media

Due to the existence of coke particles, the casting of hot metal is a typical fluid flow in porous media. The volume-averaged continuity, momentum and energy equations have been developed. The interaction between liquid and coke particle is modelled through Ergun's equation [16]. The empirical correlation given by Kuwahara and Nakayama [17] in the transverse direction was applied to account for thermal dispersion as the liquid iron flows through the porous media.

- Natural convection 
Because the fluid flow in the hearth is determined by both forced and natural convection $[5,18]$, the buoyancy force, i.e. $\varepsilon\left(\rho-\rho_{\text {ref }}\right) \boldsymbol{g}$, caused by the density variation due to the thermal expansion, has been considered in the momentum equation. $\rho_{\text {ref }}$, a constant reference density, is set to be the density of liquid iron at $1550^{\circ} \mathrm{C}$. For this study, $\rho_{\text {ref }}=6825 \mathrm{~kg} \cdot \mathrm{m}^{-3}$.

- Turbulence flow

The K-omega based Shear Stress Transport (SST) model [19, 20] is applied to predict the effect of flow variation in time and space on flow characteristics. The SST model works by solving a k-omega model near the wall and k-epsilon model in the free stream. It is expected to more accurately predict the near-wall flow and heat transfer. The eddy viscosity, $\mu_{t}$, calculated by SST model, is used to account for the turbulence effect, which has been implemented in momentum and thermal energy equations.

\subsection{Computational domain and material properties}

For the casting through one taphole of furnace, the liquid flow and heat transfer in the hearth is symmetric. The symmetry plane can be defined by the hearth centreline and the taphole. So, in order to improve the computational efficiency, only half of the hearth is modelled. The hearth geometry of BF5 and the thermocouple locations are shown in Fig. 1. The hearth of furnace is $\sim 10.6 \mathrm{~m}$ in the inner diameter.

All the thermocouples are within the carbon blocks (Fig. 1), the general arrangement of which is shown (by the dots) in the pad and along the sidewall. There are three horizontal layers of thermocouples in the hearth pad and two vertical layers in the hearth sidewalls at different levels. Note that only the outer layer of thermocouples in the sidewall is shown in Fig. 1.

The computational domain is composed of a liquid (molten iron) domain and a solid (refractory) domain. Because there is a complex coupling between liquid flow and heat transfer in the liquid iron bath, a fully structured hexahedral mesh in the liquid bath was generated as shown in Fig. 2(a), which attempts to improve the solution accuracy and also reduces the number of elements, faces and edges in the simulation. For the refractory part of hearth, as shown in Fig. 2(b), only a tetrahedral un-structured mesh was applied as there are no convergence issues in terms of heat conduction in the solid domain (refractory).

Typical material properties used in the simulation for liquid iron, hearth refractory and coke bed are listed in Table 2. Most properties are temperature (T)-dependent. Coke particles with a $0.03 \mathrm{~m}$ diameter are uniformly distributed in the bed. A coke bed porosity of 0.35 was used. In the simulation, carbon content of iron is assumed to be $3.75 \mathrm{wt} \%$. The temperature dependent property of refractory conductivity is obtained based on the provided discrete temperature values. Below the solidus temperature of $1150^{\circ} \mathrm{C}$, the solidification of iron is modelled using a high viscosity [15]. The following expression for viscosity of iron was applied:

$$
\mu=3.669 \times 10^{-4} e^{41400 / R T} \cdot \min \left(1 \times 10^{5}, e^{\max (0,0.5(1423.15-T)}\right)
$$

\subsection{Boundary conditions}

In the current campaign of BF5, there is a clear cyclic variation of temperatures in the hearth pad as shown in Fig. 3. With regards to the local minimum and maximum temperatures, five typical scenarios have been selected for analysis, denoted by arrows in Fig. 3 and listed as follows: 
- Scenario 1 - First local minimum plug temperature post blow-in (10 Sept, 2009)

- Scenario 2 - Occurrence of the first quasi-steady state peak temperature (25 Sept, 2009)

- Scenario 3 - First long period with a small temperature fluctuation (22 May, 2010)

- Scenario 4 - Second long period with relatively stable plug temperature (2 May, 2011)

- Scenario 5 - Peak plug temperature representing hearth status in 2013 (9 February, 2013)

Daily averaged temperatures from the thermocouples at the side wall and hearth bottom have been applied in each scenario as the boundary condition of numerical simulation.

The implementation of boundary conditions is as follows:

- Inlet

At the inlet boundary, the liquid iron temperature is set to a constant temperature, typically $1550^{\circ} \mathrm{C}$. The inlet flowrate is uniformly distributed and adjusted to match the daily production.

- Outlet

Pressure outlet boundary condition is set at the taphole outlet.

- Wall

The outer face of the side-wall is aligned with the wall thermocouples and the bottom wall aligned with pad thermocouples at GL+2906, the lowest row of thermocouples, which guarantees the temperature reading from these thermocouples can directly give the boundary condition for the side and bottom walls.

- Interface

Heat transfer through the interface is set to conservative interface flux, guaranteeing a seamless transfer through the boundaries of different domains.

- Coke bed

The liquid domain includes the coke bed, coke free layer (CFL) and taphole. The CFL depends on the coke bed position. In the simulation, for each scenario, the different coke bed positions (floating, sitting or coke bed with gutter) have been assumed and tested.

\subsection{Convergence crtiteria}

The numerical computations were performed with the general purpose computational package ANSYS-CFX 14.5, a finite volume based CFD software. The convergence is set via the following criteria:

- As a first indication for the convergence of the solution towards steady state, the root mean square (RMS) normalized values of H-Energy and K-TurbKE residuals are less than an acceptable value $\left(4 \times 10^{-5}\right)$.

- The global imbalances of mass, momentum and energy in the computational domains are less than $1 \%$.

- At the monitoring point, the absolute temperature change of the central pad temperature (GL+3907) every 1000 iterations is less than $0.5^{\circ} \mathrm{C}$. 


\section{Results and discussion}

\subsection{Typical simulation results and validation}

The fist computational run simulating the fluid flow and heat transfer in BF5's hearth was carried out for the operational conditions on 10 September 2009 (Scenario 1) when the central plug temperature decreased to a local minimum for the first time in the campaign (Fig. 3, point 1). Two different coke bed states have been assessed: (a) a fully sitting coke bed, and (b) a floating coke bed with $\Delta \mathrm{H}=0.6 \mathrm{~m}$. Note that $\Delta \mathrm{H}$ refers to the minimum height of coke free layer above the pad and the underside of the coke bed is hemi-spherically shaped. The calculated temperature distributions corresponding to these coke bed states are shown in Fig. 4. Within the solid (refractory) domain, the overall temperature distribution patterns are comparable despite different absolute values. A large temperature gradient exists within the upper ceramic cup and near the taphole, and the temperature then propagates to the external hearth wall. The influence of the taphole on the temperature distribution in the lower part of hearth refractory is limited.

However, in the liquid (iron) domain, the temperature distributions are quite different for the above two coke bed states. For the fully sitting coke bed case, the temperatures in the lower part of hearth changes significantly. Over a vertical height of $1.5 \mathrm{~m}$, the temperature difference is approximately $400^{\circ} \mathrm{C}$. In contrast, for the floating coke bed case, the temperature in the liquid iron bath is relatively uniform. These temperature distributions highlight the significant effect of coke bed states on the heat transfer in the hearth.

In order to better understand the temperature distribution in the liquid iron bath, the velocity field and streaklines are shown in Fig. 5. All the results show a fast moving region near the upper part of hearth. In the near-taphole region, most of the liquid iron flows directly towards the taphole (from the inlet boundary) reflecting the strong forced convection; on the opposite side of taphole, the liquid flows preferentially towards the wall, mainly driven by the strong thermally-driven buoyancy force near the wall. Due to the hearth cooling, the liquid near the wall continuously loses enthalpy through the wall, resulting in both liquid iron temperature and density changes, which drives the fast liquid flow near the wall.

In the lower part of hearth, the flow behaviour is quite different for the various coke bed positions. For the sitting coke bed, a stagnant region is formed in the lower part of hearth. Heat transfer in this region is dominated by heat conduction and thermal dispersion, which explains the higher temperature gradients present. For the floating coke bed, the low flow resistance in the coke free layer results in much higher iron flow near the hearth pad. Hence, more liquid can flow directly from the top inlet to the coke free layer. The enthalpy (heat) transport in the hearth is dominated by convection and hence, the temperature distribution is relatively uniform and much higher than with a sitting coke bed (Fig. 4).

In BF5, a total of 67 thermocouples are distributed across three levels in the hearth pad, i.e. GL+2906, GL+3406 and GL+3907. As mentioned in Section 2.3, the temperatures at GL+2906 are applied and used as the bottom wall boundary condition. Temperatures at the other levels, i.e. GL+3406 and GL+3907, are used for model validation. The comparison between model results and measured temperatures for 10 September 2009 are shown in Fig. 6. For the sitting coke bed, Figs. 6(a), very good agreement with dayaveraged measured data is shown. The measured temperatures are slightly asymmetric, 
likely to be a result of slight differences in refractory arrangement and/or thermocouple position. For the floating coke bed case, the predicted temperatures are higher than measured, particularly at the highest level (GL+3907).

In summary, the above comparison demonstrates that the sitting coke bed is the most likely hearth condition for this early period in BF5's campaign. Although the effect of other factors such as coke particle size and bed porosity distribution cannot be fully excluded, the good agreement between measured and predicted data for a sitting bed does support this set-up of the hearth geometry/meshing and the feasibility of proposed numerical model.

Interestingly, if we examine more closely the flow in the upper part of hearth using a three-dimensional streakline distribution plot, Fig. 7, it is clear that although the liquid iron enters the hearth uniformly, the flow behaviour is still quite complex. Particularly near the sidewall, rather than flowing directly towards the taphole, the liquid entering the hearth flows towards the wall and then either directly, or around the periphery, towards the taphole. A consequence of this flow distribution is the intensive flow near the taphole and associated high shear stresses in the middle of the hearth sidewall along the vertical direction; this confirms the conclusion based on the observation of the flow field shown at the symmetric plane of Fig. 5(a).

To further illustrate the effect of buoyancy force on the near-wall flow behaviour, Figure 8 shows the local velocity field near the taphole and on the opposite side. On the opposite side of the taphole, the near wall velocity of liquid iron increases as the elevation decreases. Due to the relative stagnant flow in the lower part of the hearth, the flow abruptly turns towards the taphole which causes the highest shear stresses in the middle of sidewall. A closer examination of the velocity field shows that a very thin film of liquid iron near the wall penetrates the stagnant flow region near the bottom of hearth. It is also worth noting that there is a significant velocity increase near the refractory steps which were present at this point in the campaign, which is mainly buoyancy force driven.

\subsection{Analysis of plug temperature trend in a long term}

In Section 2.3, the hearth pad temperature trend over the first five years of the current BF5 campaign was introduced (Fig. 3). Over a shorter time span, the pad temperature fluctuations observed are mainly due to the change in flow distribution related to different coke bed conditions. Over a longer time span, the temperature variation is also influenced by the hearth pad wear. Hence, the campaign life of BF5 hearth is closely linked to peak pad temperatures. Since the start of the current campaign, a number of typical scenarios have been selected for analysis and understanding of peak temperatures. For each scenario, with essentially intact hearth geometry, various coke bed conditions, sitting or floating, have been assumed and tested using CFRM.

Amongst the numerous cases studies, the best comparisons are shown in Fig. 9, together with the schematic of corresponding coke bed positions. Early in the campaign, the assumption of a sitting coke bed with large gutter and a floating coke bed with a CFL $0.3 \mathrm{~m}$ high results in a very good comparison between predicted and measured refractory temperatures (Fig. 13 - Scenario 2\&3). With a hearth geometry assumed to be intact, the peak temperatures observed are clearly caused by the intensive liquid flow distribution generated as the coke bed floats upward.

For Scenario 4 (2 May 2011), the slight increase in the maximum pad temperature suggests a coke bed with a higher CFL $(0.6 \mathrm{~m}$ is assumed) or some minor wear of the 
hearth pad. Considering there is a long period with a small temperature fluctuation, 2 May 2011 - 12 April 2012, the higher position of the floating bed appears to be a reasonable assumption. However, for Scenario 5 (9 February 2013), the measured pad temperature is higher compared with model predictions with a CFL of $0.6 \mathrm{~m}$ and it indicates that the hearth pad has experienced some wear.

Hence, in a longer term, hearth refractory wear and coke bed condition cannot be completely differentiated; however, it is essential that a consistent evolution of the refractory wear, in particular, must be imposed on such an analysis.

\section{Conclusion}

Coupled Flow and Refractory Model (CFRM) has been upgraded based on a new and improved CFX platform, the new hearth geometry of BlueScope's No. 5 Blast furnace and the Shear Stress Transport turbulence model. In this paper, the role of the thermally-induced buoyancy flow is highlighted since this causes a more complex iron flow distribution in the hearth. The model is validated through a comparison between measured refractory data and model predictions. The actual range in measured pad temperature fluctuation is well within the temperature difference related to the coke bed movement from a sitting to a floating bed condition.

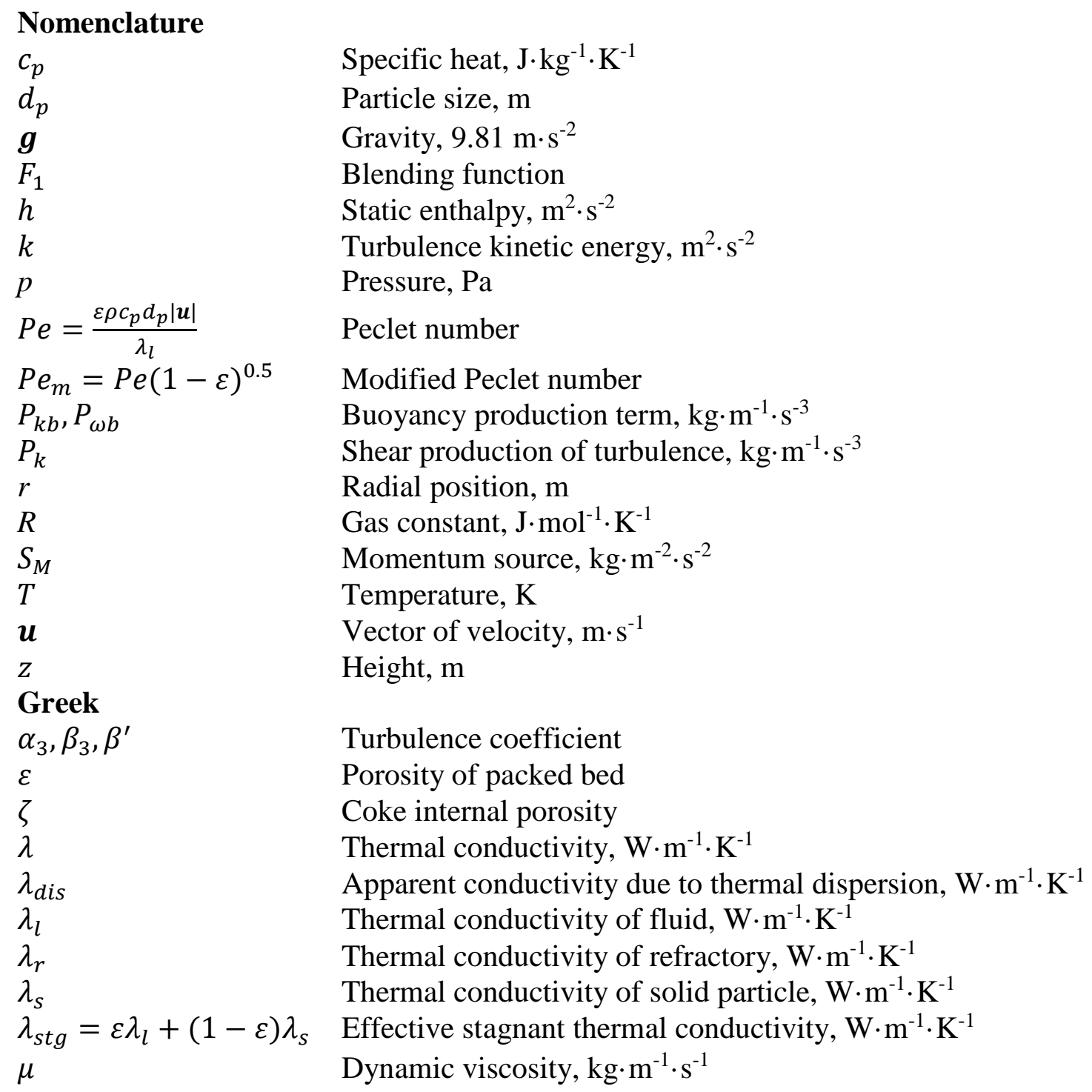




$\begin{array}{ll}\mu_{t} & \text { Turbulence viscosity, } \mathrm{kg} \cdot \mathrm{m}^{-1} \cdot \mathrm{s}^{-1} \\ \rho & \text { Density, } \mathrm{kg} \cdot \mathrm{m}^{-3} \\ \rho_{\text {ref }} & \text { Reference density, } \mathrm{kg} \cdot \mathrm{m}^{-3} \\ \sigma_{k}, \sigma_{T}, \sigma_{\omega} & \text { Turbulence model constant } \\ \tau & \text { Shear stress, } \mathrm{kg} \cdot \mathrm{m}^{-1} \cdot \mathrm{s}^{-2} \\ \phi & \text { Shape factor of coke particles } \\ \omega & \text { Turbulence frequency, } \mathrm{m}^{2} \cdot \mathrm{s}^{-2}\end{array}$

\section{Acknowledgments}

The authors gratefully acknowledge Dr. H. Zughbi and Mr. M. Biasutti (BlueScope Ltd), and Dr. B. Guo and Mr. K. Komiyama (formerly, University of New South Wales) for their valuable discussions. The authors also thank BlueScope Ltd for the permission to publish the results.

\section{References}

1. Dong XF, Zulli P, Biasutti M. Prediction of blast furnace hearth condition: Part II A transient state simulation of hearth condition during blast furnace shutdown. Ironmaking and Steelmaking. 2018 (submitted for publication).

2. Yoshikawa F, Szekely J. Mechanism of blast furnace hearth erosion. Ironmaking and Steelmaking. 1981;8(4):159-68.

3. Ohno J, Nakamura M, Hara Y, et al. Flow of iron in blast furnace hearth. Symposia Series - Australasian Institute of Mining and Metallurgy1981. p. 10.1-10.12.

4. Shibata K, Kimura Y, Shimizu M, et al. Dynamics of dead-man coke and hot metal flow in a blast furnace hearth. ISIJ International. 1990;30(3):208-215.

5. Preuer A, Winter J, Hiebler H. Computation of the iron flow in the hearth of a blast furnace. Steel Research. 1992;63(4):139-146.

6. Preuer A, Winter J, Hiebler H. Computation of the erosion in the hearth of a blast furnace. Steel Research. 1992;63(4):147-151.

7. Kowalski W, Bachhofen HJ, Ruther HP, et al. Investigation on tapping strategies at blast furnace with special regard to the state of hearth. Ironmaking Conf.: Iron and Steel Society; 1998. p. 595-606.

8. Takatani K, Inada T, Takata K. Mathematical model for transient erosion process of blast furnace hearth. ISIJ International. 2001;41(10):1139-1145.

9. Luomala MJ, Mattila OJ, Härkki JJ. Physical modelling of hot metal flow in a blast furnace hearth. Scandinavian Journal of Metallurgy. 2001;30(4):225-231.

10. Panjkovic V, Truelove JS, Zulli P. Numerical modelling of iron flow and heat transfer in blast furnace hearth. Ironmaking and Steelmaking. 2002;29(5):390-400.

11. Wright B, Zulli P, Bierbrauer F, et al. Assessment of refractory condition in a blast furnace hearth using computational fluid dynamics. Third International Conference on CFD in the Process Industries; 10-12 December; Melbourne, Australia2003.

12. Cheng WT, Huang CN, Du SW. Three dimensional iron flow and heat transfer in the hearth of a blast furnace during tapping process. Chemical Engineering Science. 2005;60(16):4485-4492.

13. Maldonado D, Zulli P, Guo BY, et al. Mathematical modelling of flows and temperature distributions in the blast furnace hearth. Fifth International Conference on CFD in the Process industries; 13-15 December; Melbourne, Australia2006.

14. Guo BY, Maldonado D, Zulli P, et al. CFD modelling of liquid metal flow and heat transfer in blast furnace hearth. ISIJ International. 2008;48(12):1676-1685. 
15. Komiyama KM, Guo BY, Zughbi H, et al. Improved CFD model to predict flow and temperature distributions in a blast furnace hearth. Metallurgical and Materials Transactions B. 2014;45(5):1895-1914.

16. Ergun S. Fluid flow through packed columns. Chemical Engineering Progress. 1952;48:89-94.

17. Kuwahara F, Nakayama A. Numerical determination of thermal dispersion coefficients using a periodic porous structure. Journal of Heat Transfer. 1999;121(1):160-163.

18. Zulli P. Blast furnace hearth drainage, with and without a coke-free layer [Ph.D.]: University of New South Wales; 1992.

19. ANSYS Inc., ANSYS CFX-14.5-User Online Manual, 2013.

20. Menter FR. Two-equation eddy-viscosity turbulence models for engineering applications. AIAA Journal. 1994;32(8):1598-1605.

21. Jimbo I, Cramb AW. The density of liquid iron-carbon alloys. Metallurgical and Materials Transactions B. 1993;24(1):5-10.

22. Gale WF, Totemeier TC. Smithells Metals Reference Book. Oxford: Elsevier Butterworth-Heinemann; 2004.

23. Biasutti M. Personal communication. BlueScope Ltd., Port Kembla, Australia, 2003.

24. Desai B, Ramna RV, Dash SK. Optimum coke free space volume in blast furance hearth by wall shear strees analysis. ISIJ International. 2006;46(10):1396-1402. 
Table 1 Governing equations

\begin{tabular}{|c|c|}
\hline Equations & Descriptions \\
\hline \multicolumn{2}{|c|}{ For liquid flow and heat transfer in the liquid domain } \\
\hline $\begin{array}{l}\text { Continuity } \\
\text { equation }\end{array}$ & $\nabla \cdot(\varepsilon \rho \boldsymbol{u})=0$ \\
\hline $\begin{array}{l}\text { Momentum } \\
\text { equation }\end{array}$ & $\begin{array}{l}\nabla \cdot(\varepsilon \rho \boldsymbol{u} \otimes \boldsymbol{u})=-\varepsilon \nabla p+\nabla \cdot \boldsymbol{\tau}+\varepsilon\left(\rho-\rho_{\text {ref }}\right) \boldsymbol{g}+\boldsymbol{S}_{M} \\
\boldsymbol{\tau}=\varepsilon \mu_{e f f}\left[\nabla \boldsymbol{u}+(\nabla \boldsymbol{u})^{T}\right] \\
\mu_{e f f}=\mu+\mu_{t} \\
\boldsymbol{S}_{\boldsymbol{M}}=-\varepsilon\left[150 \mu \frac{(1-\varepsilon)^{2}}{\varepsilon^{2}\left(\phi d_{p}\right)^{2}}+1.75 \rho \frac{1-\varepsilon}{\varepsilon \phi d_{p}}|\boldsymbol{u}|\right] \boldsymbol{u}\end{array}$ \\
\hline $\begin{array}{l}\text { Thermal energy } \\
\text { equation }\end{array}$ & $\begin{array}{ll}\nabla \cdot(\varepsilon \rho \boldsymbol{u} h)=\nabla \cdot\left(\lambda_{e f f} \nabla T\right) & \\
\lambda_{\text {eff }}=\left(\lambda_{s t g}+\varepsilon \frac{c_{p} \mu_{t}}{\sigma_{T}}\right) \boldsymbol{\delta}+\lambda_{\text {dis }} & \\
\lambda_{\text {stg }}=\varepsilon \lambda_{l}+(1-\varepsilon) \lambda_{s} & \\
\lambda_{\text {dis }}=0.022 P e_{m}^{1.7}(1-\varepsilon)^{-0.25} \lambda_{l} & \text { for } P e_{m}<10 \\
\lambda_{\text {dis }}=0.052 P e_{m}(1-\varepsilon)^{0.5} \lambda_{l} \quad \text { for } P e_{m} \geq 10\end{array}$ \\
\hline $\begin{array}{l}\text { Shear Stress } \\
\text { Transport } \\
\text { model }\end{array}$ & $\begin{aligned} \nabla \cdot(\varepsilon \rho \boldsymbol{u} k)= & \nabla \cdot\left[\varepsilon\left(\mu+\frac{\mu_{t}}{\sigma_{k 3}}\right) \nabla k\right]+\varepsilon P_{k}-\beta^{\prime} \varepsilon \rho k \omega+\varepsilon P_{k b} \\
\nabla \cdot(\varepsilon \rho \boldsymbol{u} \omega)= & \nabla \cdot\left[\varepsilon\left(\mu+\frac{\mu_{t}}{\sigma_{\omega 3}}\right) \nabla \omega\right]+\left(1-F_{1}\right) 2 \varepsilon \rho \frac{1}{\sigma_{\omega 2} \omega} \nabla k \cdot \nabla \omega \\
& +\alpha_{3} \varepsilon \frac{\omega}{k} P_{k}-\beta_{3} \varepsilon \rho \omega^{2}+\varepsilon P_{\omega b}\end{aligned}$ \\
\hline \multicolumn{2}{|c|}{ For heat transfer in the refractory solid domain } \\
\hline $\begin{array}{l}\text { Thermal energy } \\
\text { equation }\end{array}$ & $\nabla \cdot\left(\lambda_{r} \nabla T\right)=0$ \\
\hline
\end{tabular}


Table 2 Material Properties

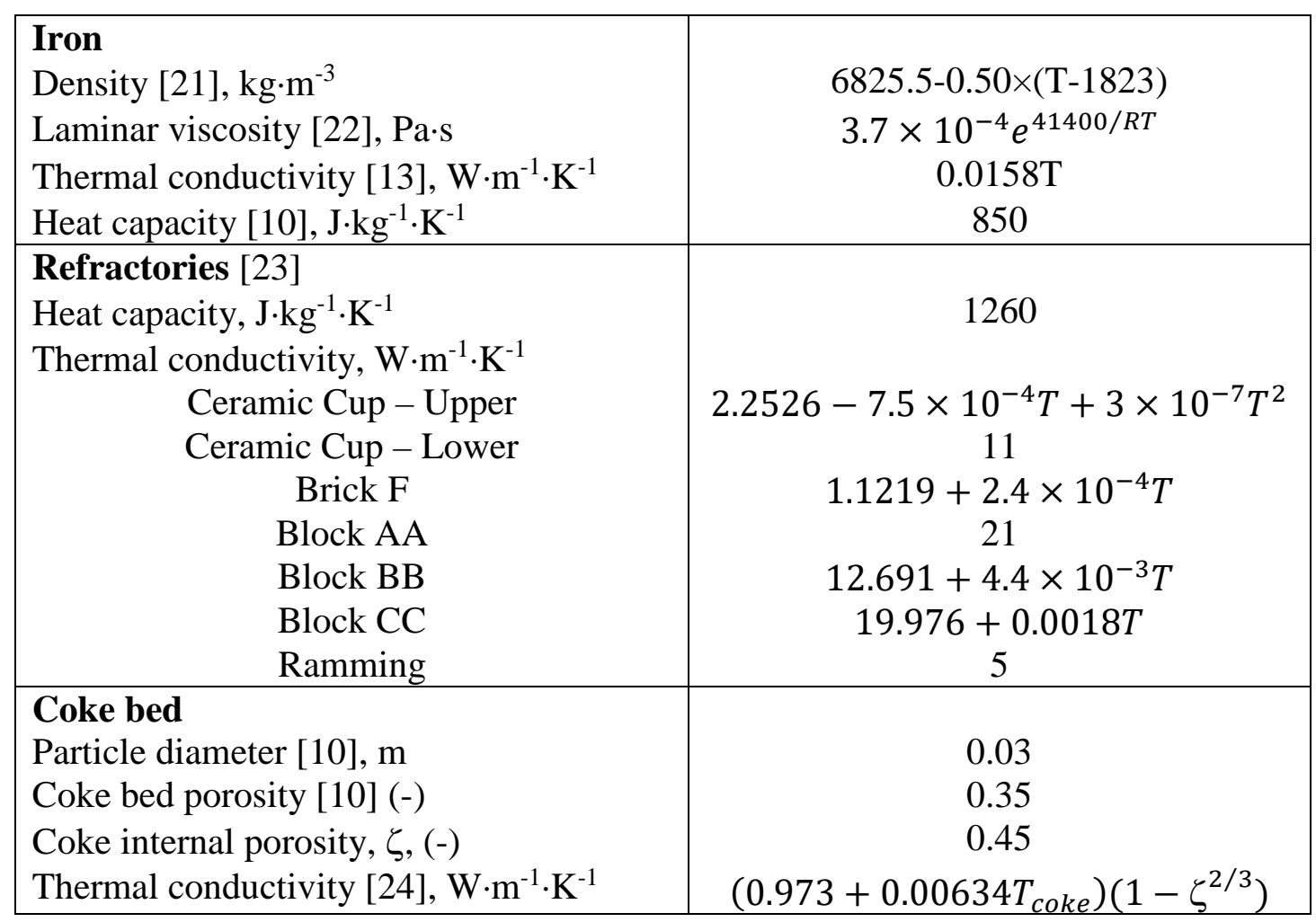




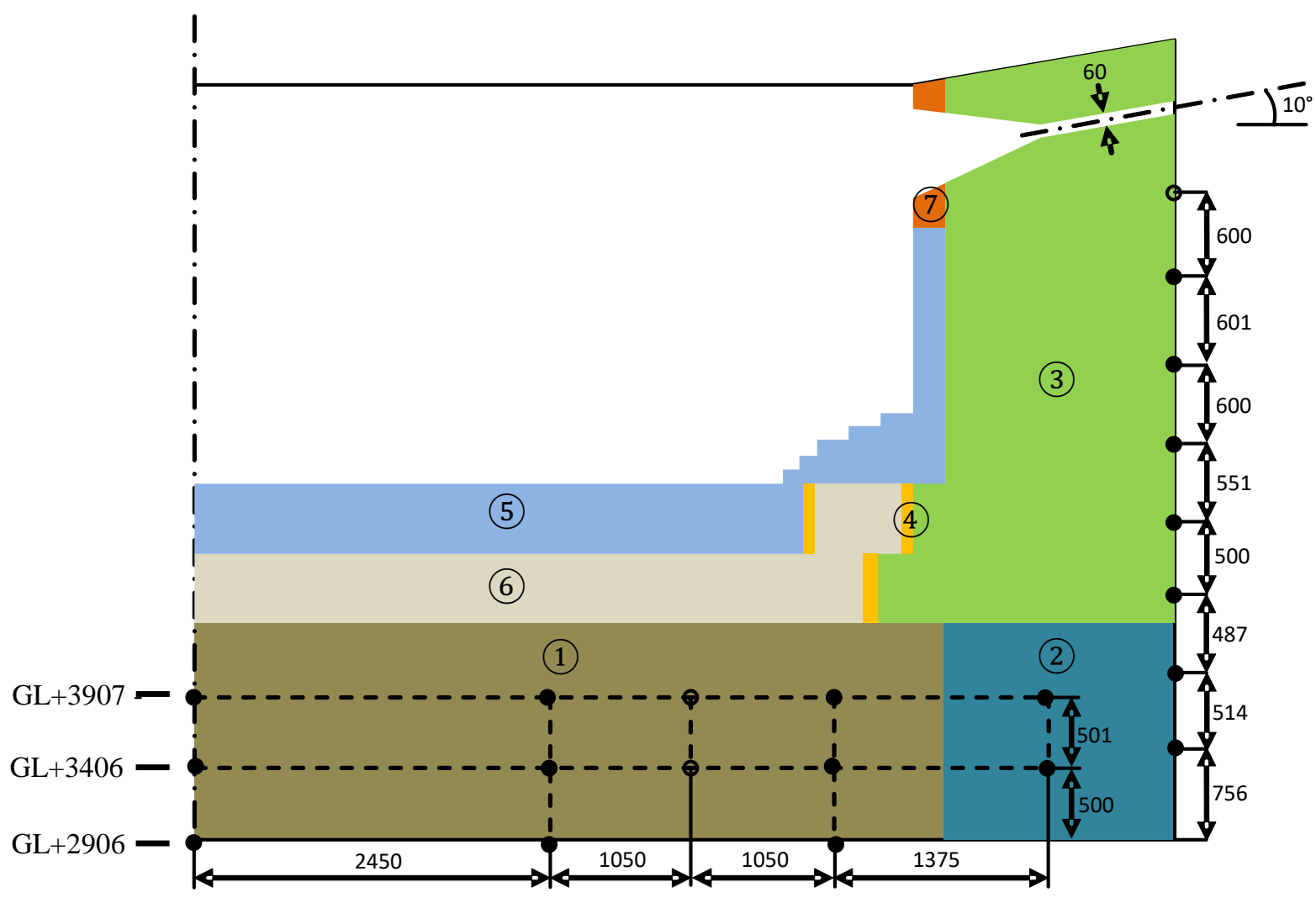

(1) Block AA; (2) Block BB; (3) Block CC; (4) Ramming;

(5) Upper Ceramic Cup; (6) Lower Ceramic Cup; 7 Brick U7.

Figure 1 Geometric dimensions of the hearth of BF5 and the locations of thermocouples (unit: $\mathrm{mm}$ ). [Note that the vertical coordinate starts from the ground level (GL).] 


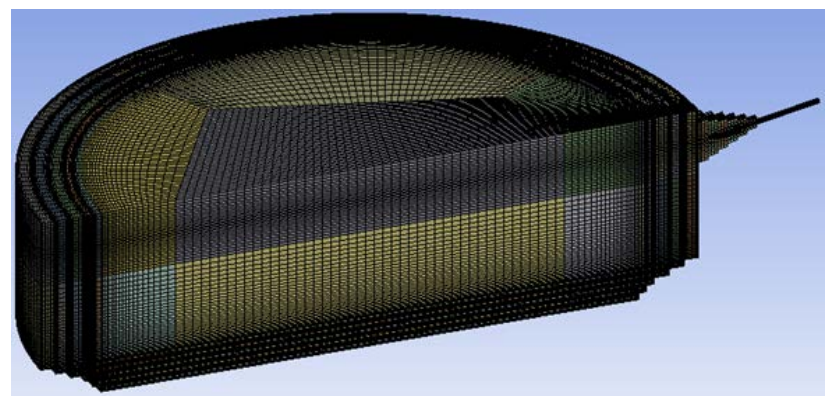

(a)

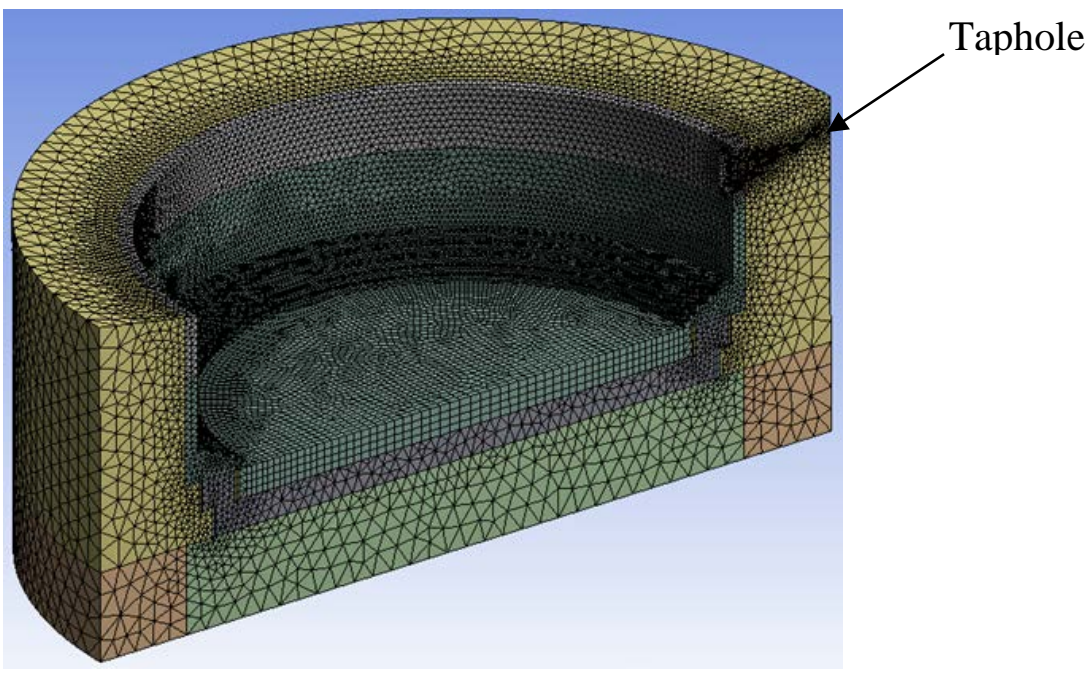

(b)

Figure 2 Computational grid for the hearth geometry: (a) liquid bath and (b) hearth refractory. 


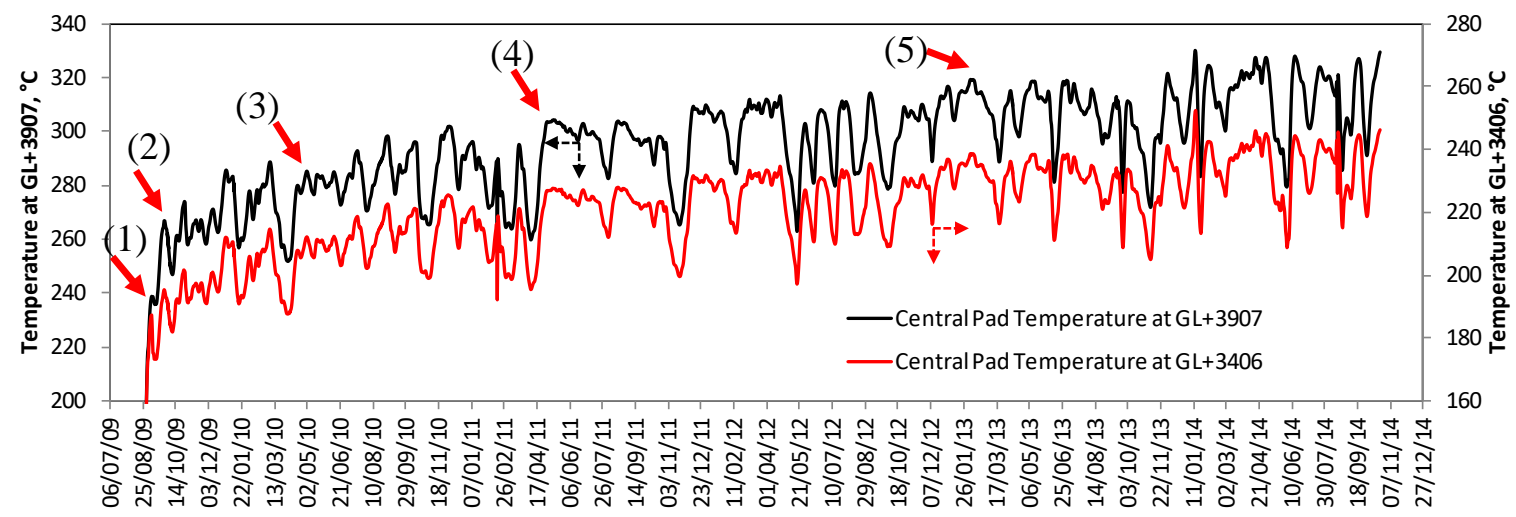

Figure 3 Central pad temperatures at the levels of GL +3406 and GL+3907 from the start of $4^{\text {th }}$ campaign to the end of year 2014 . 


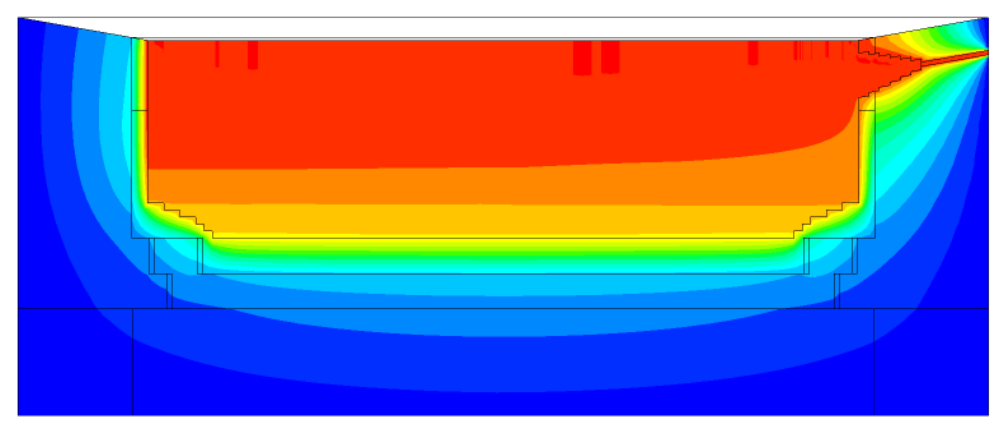

(a)

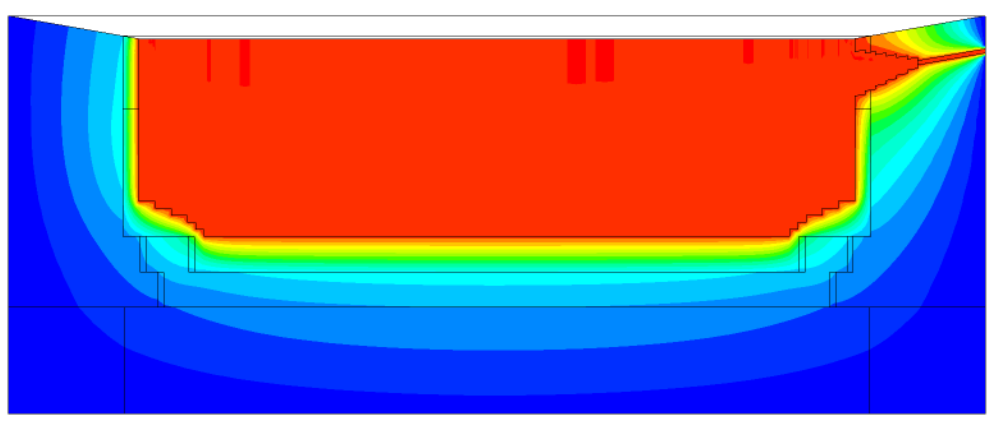

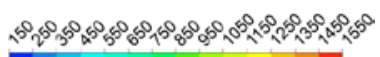

(b)

Figure 4 Calculated temperature distributions in the hearth for (a) fully sitting coke bed state and (b) floating coke bed with $\Delta \mathrm{H}=0.6 \mathrm{~m}$. 

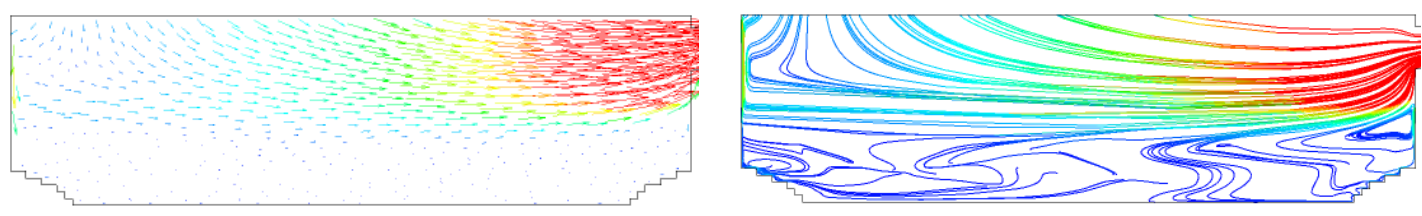

(a)
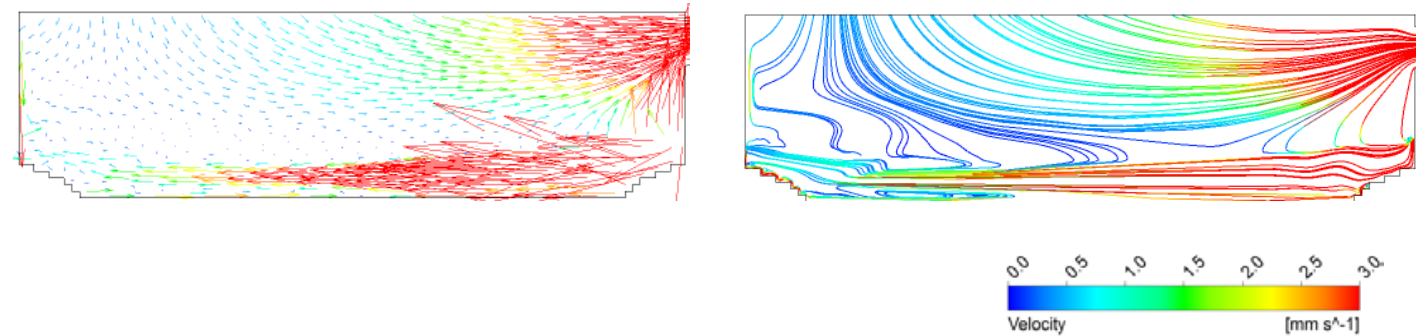

(b)

Figure 5 Velocity fields and streaklines in the liquid bath for (a) fully sitting coke bed state and (b) floating coke bed with $\Delta \mathrm{H}=0.6 \mathrm{~m}$. 


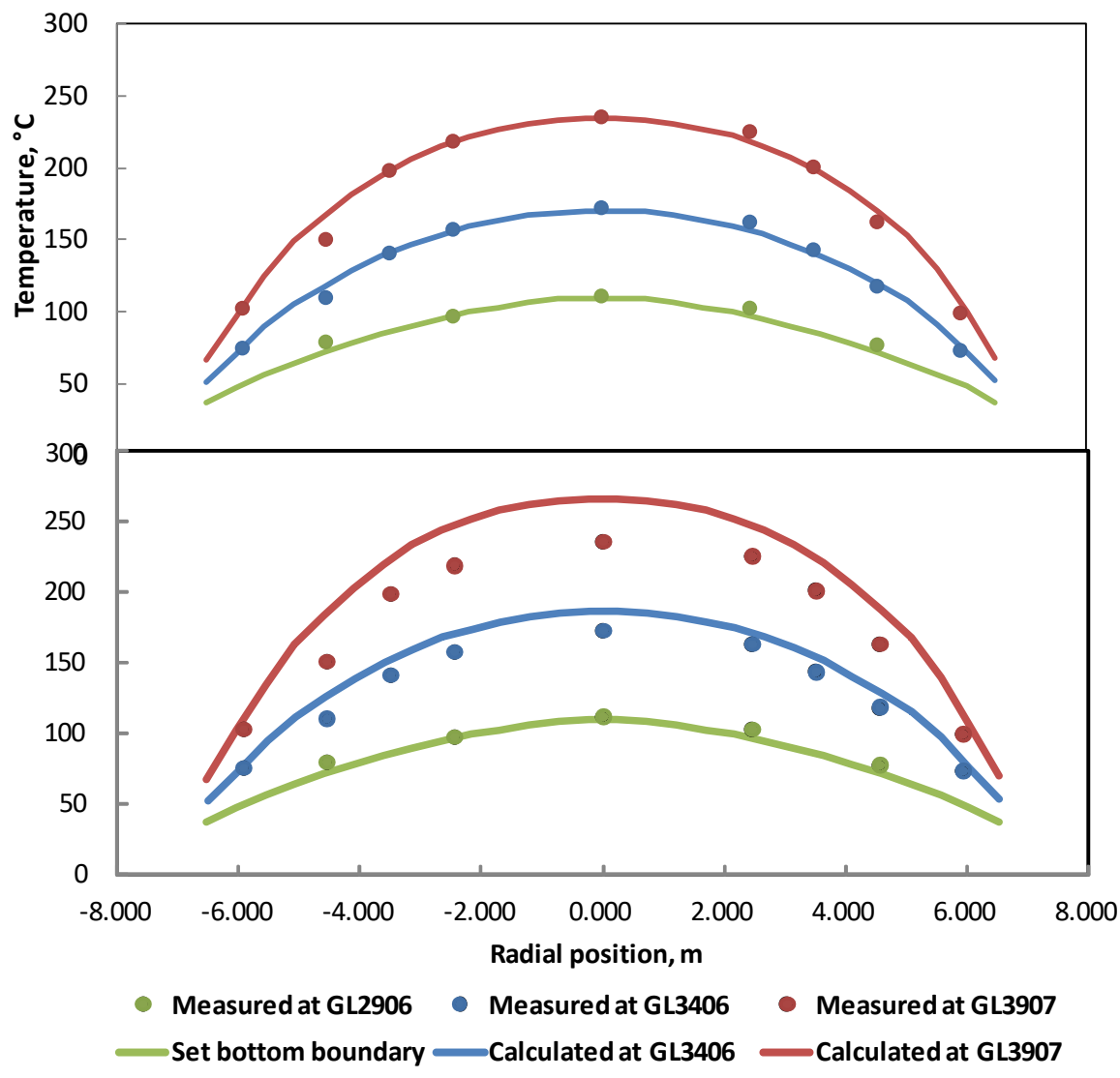

(a)

(b)

Figure 6 Comparison between measured data and calculated results for (a) fully sitting coke bed and (b) floating coke bed with $\Delta \mathrm{H}=0.6 \mathrm{~m}$. 


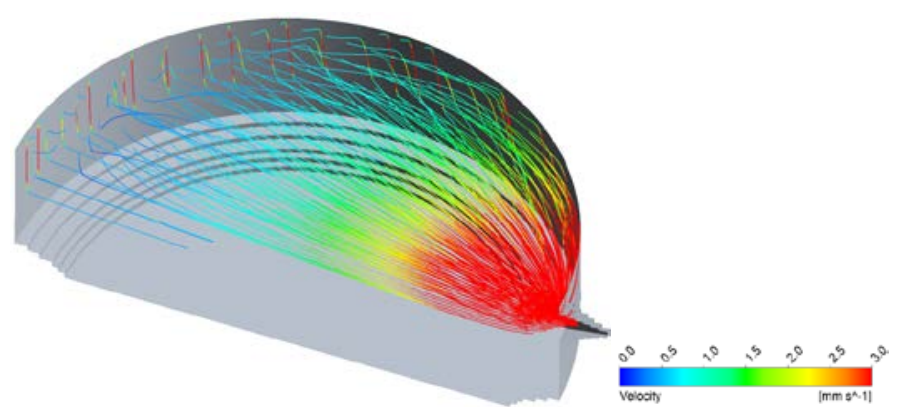

Figure 7 3D streakline distribution starting from the inlet boundary. 


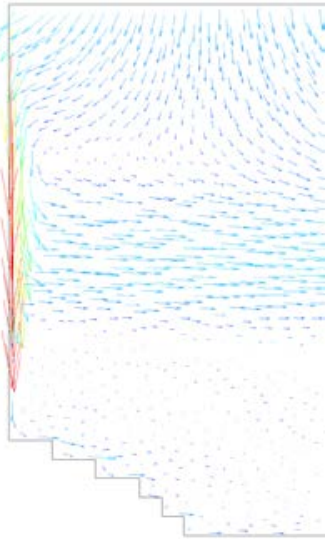

(a)

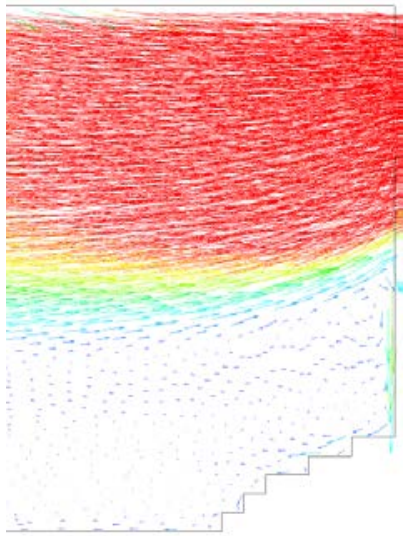

(b)

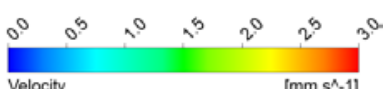

[mm s^-1]

Figure 8 Local velocity fields at (a) the opposite side of taphole and (b) the taphole side in the symmetric plane. 

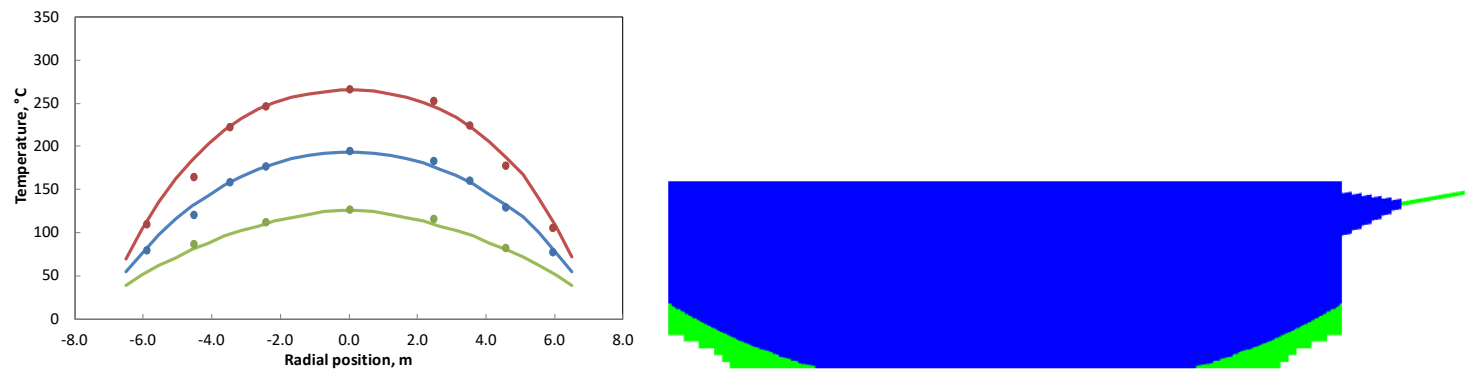

(Scenario 2)
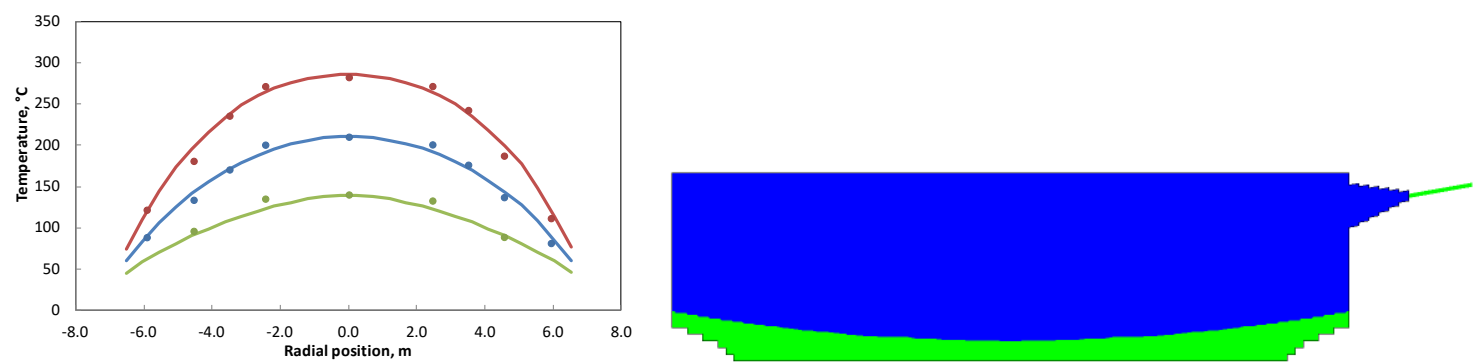

(Scenario 3)
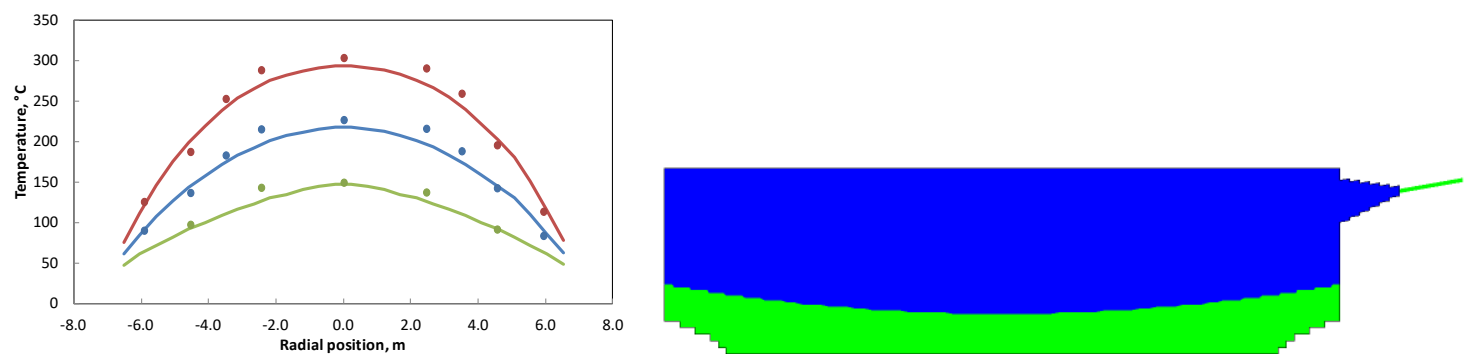

(Scenario 4)
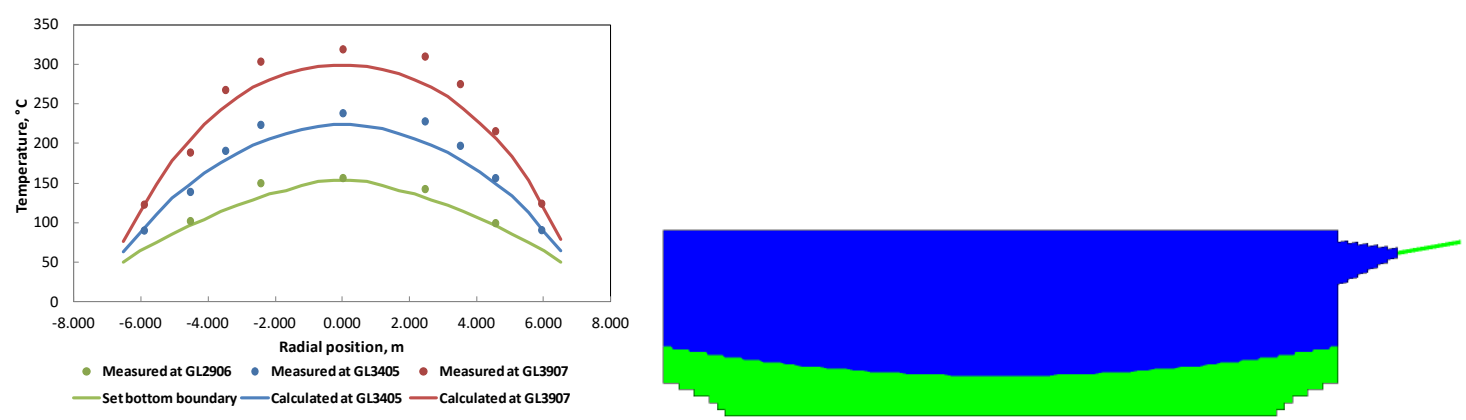

(Scenario 5)

Figure 9 Comparison between measured and calculated results for scenarios (2)-(5) with assumed coke bed states. 
A list of figure captions:

Figure 1 Geometric dimensions of the hearth of BF5 and the locations of thermocouples (unit: $\mathrm{mm}$ ). [Note that the vertical coordinate starts from the ground level (GL).]

Figure 2 Computational grid for the hearth geometry: (a) liquid bath and (b) hearth refractory.

Figure 3 Central pad temperatures at the levels of GL +3406 and GL+3907 from the start of $4^{\text {th }}$ campaign to the end of year 2014 .

Figure 4 Calculated temperature distributions in the hearth for (a) fully sitting coke bed state and (b) floating coke bed with $\Delta \mathrm{H}=0.6 \mathrm{~m}$.

Figure 5 Velocity fields and streaklines in the liquid bath for (a) fully sitting coke bed state and (b) floating coke bed with $\Delta \mathrm{H}=0.6 \mathrm{~m}$.

Figure 6 Comparison between measured data and calculated results for (a) fully sitting coke bed and (b) floating coke bed with $\Delta \mathrm{H}=0.6 \mathrm{~m}$.

Figure 7 3D streakline distribution starting from the inlet boundary.

Figure 8 Local velocity fields at (a) the opposite side of taphole and (b) the taphole side in the symmetric plane.

Figure 9 Comparison between measured and calculated results for scenarios (2)-(5) with assumed coke bed states. 